\title{
'Quality is bound up with our values': evaluating the quality of mentoring programmes
}

\section{W. McMillan \& M.E. Parker}

\begin{abstract}
This paper discusses quality evaluation of health sciences mentoring programmes. The discussion highlights the way in which perceptions of what constitutes quality shape evaluative purposes. Potential tensions between the evaluative purposes of various stakeholders are brought to the fore. To this end, the discussion explores the ways in which accountability shapes the evaluative purposes of funders and how the desire for programme knowledge and development frames the evaluative purposes of academics. Various approaches to programme evaluation are examined. The potential of reflective practice as a tool for examining quality for knowledge and development of programmes is considered. The paper concludes by presenting a framework for evaluating various aspects of quality in mentoring programmes.
\end{abstract}

Keywords: accountability; evaluative purpose; health sciences education; mentoring programmes; quality evaluation; transformation.

\section{Introduction}

Quality evaluation, the assessing and enhancing of teaching and learning in higher education, has been placed squarely on the contemporary agenda in higher education (Newton, 2002). Evaluation of the quality of mentoring programmes in higher education is no exception in this regard (Miller, 2002, pp. 237-59). However, such evaluation is not unproblematic. As Watty (2003) highlighted, there are different ways of conceptualizing quality in the context of higher education. These conceptualizations, according to Vroeijenstijn (1992), come about because a variety of stakeholders have an interest in the quality of higher education but not everyone has the same idea about exactly what constitutes that quality.

Pressure to measure the success rate of mentoring programmes emanates from what Chelminsky (1997) conceives of as three types of evaluative purpose. Accountability, the first of these purposes, responds to the demands of funders and stakeholders to meet contractual agreements, to gauge if programme objectives are being met and to identify successes and failures. The second and third purposes (development and knowledge) focus on improving the quality of programmes and understanding better what forms of practice are successful.

This paper explores the tensions in quality evaluation, specifically in the context of mentoring programmes for university students in South Africa. The first part of the paper briefly discusses the nature of mentoring programmes, locating the discussion within the field of health sciences education. An examination of the notion of quality follows. Potentially contradictory conceptions of quality are discussed. A framework to consider quality in higher education is then offered. The third section of the paper examines quality in the context of mentoring programmes and motivates for reflective practice and action research as a potential methodology for evaluating quality for knowledge and development. Further discussion signals potential tensions between qualitative and quantitative approaches to evaluating quality in mentoring programmes. The paper concludes by presenting a framework for evaluating various aspects of quality in mentoring programmes. 


\section{Introducing the context: mentoring in the field of health sciences education}

Mentoring programmes that service the needs of health science students are the focus of this paper. Specifically, these programmes are located in South Africa and target historically disadvantaged students. Most of these students are the first in their family, often the first in their community, to attend university. They do not have access to more experienced siblings or parents who might ease their transition into the alien environment of higher education. Foster and Russell (2002) noted that most students experience some kind of difficulty in the transition from schooling to university. However, Angelil-Carter (1998) argued that students who come from communities that have had little access to, or engagement with, universities are more likely to struggle with the transition in ways that could jeopardize successful academic performance. Consequently, the health science mentoring programmes that serve as the focus of this paper are intended to provide social emotional and academic support to these students, so as to:

ease students' transition into a dramatically new and demanding environment... ensuring that students have the support they need to function in a university setting - how to develop disciplined study habits, how to cope with stress, how to manage a budget, and access university services. (Medical Education for South African Blacks, 2003)

Freedman (1992) referred to mentoring as 'the kindness of strangers'. Explanations of the origins of mentoring draw on the Odysseus legend of Greek mythology. Odysseus entrusted his son to his wise friend and trusted advisor, Mentor, who was to guide all aspects of the boy's development. Carrad (2002) defined mentoring as a:

one-to-one, non-judgmental relationship in which an individual mentor voluntarily gives time to support and encourage another. The relationship is typically developed at a time of transition in the mentee's life, and lasts for a significant and sustained period of time.

Distinctions are usually drawn between mentoring and other types of academically supportive relationships, such as tutoring and coaching (Miller, 2002, p. 25). Mentoring is presented as holistic and of longer duration, focusing on the development of a broad spectrum of life skills (Goodlad, 1995, p. 2; Miller, 2002, p. 23). 'Planned' mentoring involves structured programmes with clear objectives, where mentors and mentees are matched using formal processes (Miller, 2002, p. 23).

Both the funders of the health sciences mentoring programme and those coordinating the mentoring programmes at different South African universities have sought ways of measuring and evaluating the quality and success of the intervention. At the heart of this endeavour was the need to define what was understood by 'quality' and to delimit the characteristics of a quality mentoring programme.

\section{Defining quality in Higher Education}

Defining 'quality', especially when the intention is to use the definition as a definitive framework for benchmarking quality in higher education, is problematic (Ratcliff, 2003; Watty, 2003). Stephenson (2003, p. 2) summarized the central problem when he noted that Many people have commented that they are able to recognize quality when they see it, but find it almost impossible to define'. This difficulty, Harvey and Newton (2004, p. 121) suggested, is 
because conceptions of quality are personal and social constructs. They argue that each stakeholder constructs a view of quality based on a select few attributes and that these selected attributes vary from stakeholder to stakeholder (Harvey \& Newton, 2004, p. 119). Criteria for selection of attributes are based on personal values and judgments (Watty, 2003, p. 214). Thus definitions of quality are, as Barnett (1992, p. 16) suggested, 'bound up with our values... [and are] connected with what we take higher education ultimately to be'.

Harvey and Green (1993, pp. 11-27) suggested five categories or ways in which quality in higher education is often conceptualized:

- as excellence, where quality is something exceptional;

- as perfection, where quality is consistent or flawless;

- as fit for purpose, where quality fulfils a perceived purpose defined by stakeholders;

- as value for money, where the subsidizing agency finds optimum benefit relative to cost;

- as transformation, where quality means enhancing and empowering the learner.

Watty (2003, p. 214) argued that these apparently separate categories have the 'potential to overlap at the margin', that stakeholder conceptions of quality may not simplistically be classified into only one of the five categories. Indeed, Lomas (2002) suggested that the Harvey and Green (1993) categories might be viewed as a matrix for defining quality.

In creating a framework for understanding conceptions of quality in higher education Watty (2003, p. 215) advocated the removal of 'perfection/consistency' from the Harvey and Green (1993) categories since higher education does not aim to produce standardized graduates, free from defects. This position echoes Lategan (1997, p. 94), who argued that the way in which 'perfection/consistency' conceptualizes quality assumes a consistent process producing a defect-free output which is inconsistent with the 'exploratory nature of higher education'.

Watty (2003, p. 215) suggested that the remaining four conceptions of quality (excellence, fit for purpose, value for money, transformation), if understood as a matrix, have the potential to form the basis of an analytical framework to consider quality in higher education. Since conceptions of quality shape how assessment of quality is conceptualized (Watty, 2003, p. 214), an understanding of these differing conceptions of quality has the potential to assist in an analysis of the priorities that various stakeholders bring to evaluating quality in higher education.

A potential tension remains in the framework outlined above: between conceptualizations of quality that highlight accountability and those that place in the forefront development and knowledge. Ratcliff (2003, p. 120) suggested that the current discourse constructs these positions as in competition.

\section{Conceptualizing quality evaluation in mentoring programmes}

The tensions noted above are played out in the process of evaluating quality in mentoring programmes, as funders highlight accountability and mentoring coordinators prioritize knowledge for programme maintenance and development. Funders, concerned with value for money, focus on efficiency and effectiveness, measuring outputs against inputs; valuing a positive correlation between money invested in a programme and successful student throughput rates. In contrast, mentoring programme coordinators voice other priorities. 
Differing conceptions of quality influence what counts as an adequate demonstration of quality and what data should be collected for that demonstration. Ratcliff (2003, p. 121) highlighted the fact that implicit assumptions about quality are often unspoken. Indeed, at the heart of the search for a mechanism for evaluating quality in mentoring programmes is the implied, but seldom voiced, question of what quality in mentoring programmes would or should be.

Biggs (2001, p. 221-22) suggested that one mechanism to help describe quality in a particular higher education context is to ask the question 'are our teaching programmes producing the results we say we want in terms of student learning?'. Rephrased for inquiry into the quality of health science mentoring programmes, the question might be posed as, is this mentoring programme making a difference? Such a question, rather than offering any direct answers, inevitably spawns a series of further questions. What is the difference that we are expecting? How will it appear? How will we recognize it? What data will serve as evidence of success? How will we measure it?

Haworth and Conrad (1997, p. xii) offered a definition of quality that provides a potential framework for answering these questions. They suggest that high quality programmes are those that 'contribute to the learning experiences of students that have positive effects on their growth and learning'. The 'difference' that a health sciences mentoring programme should be making now becomes easier to define.

The primary goal of mentoring programmes is the personal development of the mentee: to seek to shape, change and examine attitudes and values (Miller, 2002, p. 46). The focus is not specifically on the development of knowledge and skills. Any difference, therefore, would be transformational: seeking to enhance and empower. Data for quality evaluation of mentoring programmes will therefore have to indicate whether and to what extent learners have been transformed. While knowledge and skills are relatively easy to quantify, attitudes and values are more ephemeral and potentially elude quantification and evaluation. An appropriate methodology for quality evaluation in mentoring programmes thus presents a significant challenge. The selection of an appropriate research framework is at the heart of effective research and, consequently, at the heart of effective programme evaluation (Ashcroft \& Palacio, 1996, pp. 93 and 101; Biggs, 2001, p. 232; Cannon \& Newble, 2002, p. 207).

The literature highlights how most models for evaluating the quality of educational programmes fail to address that which is intrinsically human about education (Ashcroft \& Palacio, 1996, p. 113; Biggs, 2001, p. 235; Cafarella, 2002, p. 235; Stephenson, 2003, p. 4). This is not to argue that complex human processes cannot be evaluated. Indeed, there is a body of research (see, for example, Tinto, 1975; Pace, 1984; Astin, 1993; Tam, 2004) indicating that appropriate methodologies exist to investigate the influence of higher education on students' academic, social and personal growth.

Cannon and Newble (2002, p. 207) argued that 'many difficulties in evaluation are created by the implementation of poor policies and practices'. They suggest that the dominance of the quantitative paradigm in educational research has resulted in an 'obsession' with quantification. This position, Cannon and Newble argued, has led to an over-emphasis on those things that can most easily be counted (such as students' ratings of a teacher's behaviour) and an under-emphasis on those areas of academic work less easy to quantify (such as learning processes or advising students). Mentoring falls into the category of academic processes that are less easy to quantify. Biggs (2001, p. 223) suggested that quality evaluation should not be 
concerned with quantifying aspects of a system or programme. Rather, the emphasis should be on reviewing how well an institution or programme has achieved its mission and how it may be improved. The benchmarks of quality thus become practices and relationships that empower within specific teaching and learning contexts (Barrow \& Curzon-Hobson, 2003, p. 267). Tam (2004, p. 254) noted that the challenge is to find 'ways of developing and measuring outcomes that adequately reflect the full range of students' experience in higher education and provide a broader definition of the impact of higher education on student development'.

Harvey and Newton (2004, p. 157) advocated an 'evidence-based, enhancement-led' approach to quality evaluation. Such an approach draws on research-based evidence of what works and what does not (Davies et al., 2000, p. 1). Harvey and Newton (2004, p. 163) noted the specific nature of such inquiry, both in terms of context and data. They suggested that enhancement-led approaches to quality assurance require not only inquiry into structures, mechanisms and procedures, but also a clear cycle of action.

Biggs (2001, p. 223) indicated that such an approach to programme review and quality evaluation is analogous to Schon's (1983) conception of what an individual reflective practitioner does. Ashcroft and Palacio (1996, p. 94) argued that evaluation is basic to reflective practice. Evaluation, they suggested, provides the raw material for reflection, the evidence to underpin changes in action and the means by which open-mindedness and responsibility are exercised. They conceived of a cycle of action and reflection as central to effective evaluation:

We have conceptualized reflective action in teaching as an evaluation-led activity in which evaluation and the collection of data about the context for action leads to reflection on the significance of that data, and that in turn informs planning, provision and action. On the completion of this cycle, evaluation again takes place, this time into the effectiveness of action, leading to another cycle of reflection, planning and action. (Ashcroft \& Palacio, 1996, p. 94)

Ashcroft and Palacio (1996, pp. 94-5) noted that their model of reflection has much in common with the model of action research developed by Stenhouse (1987). Both require inquiry into practice, are centered on the improvement of practice and each may empower the educator and are based on the belief that the practitioner is the best person to determine the foci for evaluation and to control and interpret the resulting data. Ashcroft and Palacio (1996, p. 95) argued that the close relationship between the conception of reflective practice and action research makes action research a particularly appropriate model for an evaluationbased inquiry into practice.

Action research is a potentially suitable tool for mentorship coordinators in their inquiry into the quality of mentoring programmes. First, it is a model specifically designed to examine human endeavors like education (Boxer, 1985; Ashcroft \& Palacio, 1996). Second, because action research focuses specifically on practice it is eminently suited to address research into the development and knowledge of the quality of mentoring programmes (Ashcroft \& Palacio, 1996; Biggs, 2001).

Accountability versus development and knowledge: potentially contradictory agendas However, while action research may be suited to the development and knowledge purposes of programme evaluation, it may be less appropriate to address the demands of accountability. 
Action research has the potential to produce data that is designed to evaluate and improve a practice (Cohen et al., 2000, p. 79), but it is not ideally designed to gather the data necessary for generalizations. Research that investigates accountability collects data to answer the question 'what is happening?' In contrast, research for development and knowledge, asks not only 'what is happening', but also wants to know why. Different research approaches may best serve these two research questions.

Biggs (2001, p. 232) argued that two broad sets of assumptions are used when people think about learning and teaching; quantitative and qualitative. He suggested that quantitative methods and tools are well suited to collecting data relating to 'what' and that qualitative method and tools are more appropriate for examining the 'why'. Ratcliff (2003, p. 127) contested this position, arguing that context particularizes any research question. He holds that the classic distinction between quantitative studies (traditionally held to provide data from which generalizations can be made) and qualitative studies (traditionally held to aid in understanding dynamics internal to the situation, but failing to serve as the basis for broad generalizations) breaks down in empirical contexts. Thus, documentary and observer studies of cases of accountability can assist in framing broad contextual questions to be asked across programmes, institutions and systems and policy analyses at the system, institutional or disciplinary levels may be suggestive of points of inquiry for the single case (Ratcliff, 2004, p. 127).

Ashcroft and Palacio (1996) suggested that the choice of quantitative and qualitative approaches depends upon the purposes of the evaluation. They argued that quantitative data within predetermined categories with predetermined criteria for success may be the most appropriate approach to ensure accountability to bodies or individuals remote from the teaching context and that qualitative data that includes unintended as well as intended processes and outcomes may be particularly useful for evaluation for development and knowledge where the emphasis is on improving practice (Ashcroft and Palacio, 1996, p. 93). ${ }^{[1]}$

\section{Evaluating quality in mentoring programmes}

The development of a single tool for evaluating quality in mentoring programmes seems unlikely given the different locations of funders and mentoring programme coordinators and their consequent differing ways of conceptualizing quality in the context of higher education. Watty (2003, p. 22), discussing quality assurance commissioned by governmental quality assurance bodies, suggested that:

it may be that academics conceive quality differently to these other stakeholders, valuing different aspects of those measured and monitored under the current quality regime. If this is the case, there exists an urgent need for academics to articulate how they conceive quality in higher education.

A workshop held between funders and health sciences mentoring programme coordinators with the purpose of generating a single quality assurance tool provided an opportunity for examining the different ways in which mentoring programme stakeholders conceptualized quality. Funders, drawing only on the accountability aspect of Chelminsky's (1997) conception of evaluative purpose, desired a single tool or checklist of criteria to evaluate the effectiveness of mentoring programmes. They wanted an instrument that would measure whether the money that the organization was investing in institutional health science mentoring programmes was actually making a difference. 
Academics drew on all three of the conceptions suggested by Chelminsky (1997): accountability (to 'learners, funders, mentors, institutions, colleagues, the professional field [and] patients'), development ('make improvements', 'weaknesses - improve them', 'development', 'long term planning') and knowledge ('relevance', 'validation', 'research'). Similarly, the way in which they conceptualized quality, or the 'difference' that mentoring programmes should make, drew on various of the Harvey and Green (1993) categories simultaneously, thus suggesting the 'matrix of quality' proposed by Watty (2003, pp. 21415). Value for money ('student retention - reduce drop-out rate', 'improve 'throughput' -time needed to complete') and transformation ('improved confidence, self-esteem, cognitive abilities, psychological well-being', 'orientation/adaption/socialization into new environment') were the most commonly signaled categories. These categories were, at times, unselfconsciously presented as a single concern or definition: 'improves the institution, improves pass rates, improves teaching/learning experiences, supports staff and faculty, improves social environment on campus'. Presumably, the concern that academics had regarding accountability issues was related to the continued securing of funds to run mentoring programmes. Without funds, mentoring programmes would cease. Data that could 'prove' a positive relationship between funder investment and student throughput had the potential to satisfy donors and ensure a continued supply of funding.

Each of the characteristics of quality mentoring programmes highlighted above by programme coordinators might be defined as mentoring programme outcomes, thus answering the methodological questions posed earlier: 'what is the difference that we are expecting', 'how will it appear' and 'how will we recognize it?' Defining programme outcomes is a first step to defining, and later to measuring, quality. Drawing on this position, Lategan (1997, p. 79) argued that 'quality may be defined as the extent to which goals have been achieved'.

Within this approach, evaluating whether outcomes have been achieved would be a suitable way of answering the last two questions posed earlier: 'what data will serve as evidence of success' and 'how will we measure it?' Suitable data will demonstrate that outcomes have (or have not) been achieved. For example, if the outcome of a mentoring programme is to improve throughput, then an increase in the throughput rate of students from the mentored community as indicated by the year end mark schedule would suggest a successful mentoring programme. However, Cannon and Newble (2000, p. 211) warned against assuming a relationship between data and apparently successful outcomes. Harvey and Newton (2004, p. 156) noted that research into quality evaluation is difficult because of the impossibility of controlling all relevant factors so as to isolate causal relationships. Cannon and Newble (2000, p. 211) offered an illustrative example: a high level of student achievement may not be a valid indicator of teaching competence because of the problem of identifying the relative contribution of the teacher, the effort made by the student, the library resources available and assistance elicited from the students' peers.

Similarly, with a mentoring programme how can one be sure that successful student performance is attributable to the mentoring programme? Clearly, the year end marks alone do not constitute valid proof. Interviews with mentees, where these students explicitly attribute their academic success to the mentoring programme and provide substantiating evidence of examples where mentoring helped their academic performance, might arguably constitute more valid evidence of a relationship between a mentoring programme and the 
improved academic performance and throughput rate of the students associated with that programme.

However, Harvey and Newton (2004, p. 156) implied that such an approach alone will not necessarily provide incontestable proof. They warned that relationships between phenomena and change are not linear, but dialectical and phenomenological. They cautioned against positivistic devices that identify and isolate impacts and ignore the complexity and wider context of the phenomenon. Such an approach, they argued, ignores the complexity of intervening variables, disregards human agency and fails to take account of the 'interrelationship of the specific and the wider context in dialogical terms'. Harvey and Newton (2004, p. 156) suggested a critical epistemology approach to the interpretation of data; locating any quality evaluation within a holistic context that accounts for structure, history and ideology.

The example discussed above suggests that qualitative data (semi-structured interview responses), seeking knowledge through understanding the wider context within which the mentoring programme is located, may be more useful than quantitative evidence (student marks on the year end schedule) in attributing success to, or measuring the quality of, a mentoring programme. Ashcroft and Palacio (1996, p. 93) offered a further advantage to qualitative inquiry into the effectiveness of mentoring programmes. They suggested that 'qualitative data ... [may] include unintended as well as intended processes and outcomes'. This is of particular value in the light of criticism that an outcomes-based approach to evaluation has the potential to spawn a 'tick box mentality' (Stephenson, 2003, p. 1), that it is fragmentary (Biggs, 2001, p. 232) and that it focuses only on what is measurable and consequently neglects what is significant, such as the moral realm of human endeavors like education (Ashcroft \& Palacio, 1996, p. 113; Cafarella, 2002, p. 235; Stephenson, 2003, p. 5).

\section{Conclusion}

Qualitative approaches to data collection and analysis have the potential, therefore, to capture and inquire into the realm of attitudes and values, those aspects of educational endeavour that are difficult to capture with quantitative research methodologies. Critical approaches to qualitative inquiry are best suited to the construction of understandings that highlight complex relationships rather than seek simplistic causation.

This is not to argue that a qualitative research approach is better than the quantitative one for inquiring into the quality of mentoring programmes. The two approaches may best be put to different purposes, specifically related to whether the intention of programme evaluation is development and knowledge or accountability. Funders require evidence that their money is getting a good return. In the context of this health science mentoring programme project this means that funders ultimately wish to know that black health science students are graduating successfully within the minimum course duration because of the intervention of a project that they have funded. They will want to know how many students are benefiting in this way, in other words, the cost per student. Quantitative statistics are an appropriate tool to summarize the kind of information that funders require, what Geall et al. (1997, p. 192) referred to as 'threshold judgments relating to standards, comparability or accountability for public funds'.

Funders wish to know, in number terms, how the throughput rate has been positively influenced by the mentoring programmes that they are funding. While it requires qualitative inquiry to determine whether student academic success is attributable to the mentoring programme, it is unlikely that funders would be interested in what students had to say about 
the programme. Funders require statistics so that costs can be calculated and comparisons made. Quantitative data is appropriate to their requirements.

However, qualitative data is often a necessary prerequisite to determine whether success, as captured in quantitative data, is really attributable to a mentoring programme at all. Such data is at the heart of inquiry into programme development and knowledge, what Geall et al. (1997, p. 192) referred to as the desire to 'elucidate quality judgments with a view to enhancing the quality of provision'. Clearly then, both qualitative and quantitative research approaches are a prerequisite to an inquiry into the quality of mentoring programmes.

\section{Acknowledgements}

We would like to thank the participants of the 'Evaluating the quality of mentoring programmes' workshop, for it was their participation, feedback and concerns that gave rise to this inquiry into appropriate strategies for measuring quality in mentoring programmes.

\section{Editor's Note}

[1] The notion that qualitative and quantitative approaches constitute a dichotomy either of 'assumptions', 'purposes' or even 'epistemological positions' is naive. Biggs argument that 'quantitative and qualitative' constitute two sets of assumptions is banal. They are broad methodic approaches but there is no congruence between them and any underlying epistemological position: qualitative data can and is used for positivistic ends, for example. Furthermore, qualitative/quantitative is a simplistic dichotomy that ill reflects the research endeavour. The choice is not quantitative or qualitative: not all research is one or the other. Furthermore, and much more fundamental, it is the epistemological underpinnings of research that are the framing characteristics and despite naive attempts to propose that quantitative $=$ positive and qualitative $=$ phenomenological approaches, they do not map neatly, not least because positivist and phenomenological are not an exhaustive epistemological duality themselves. The positivist/phenomenological dichotomy ignores critical-dialectical thinking and, in some definitions, also realism.

\section{References}

Angelil-Carter, S. (Ed.), 1998, Access to Success. Literacy in academic contexts (Cape Town, UCT Press).

Ashcroft, K. \& Palacio, D., 1996, Researching into Assessment and Evaluation in Colleges and Universities (London, Kogan Page).

Astin, A.W., 1993, What Matters in College? Four critical years revisited (San Francisco, Jossey-Bass).

BARNETT, R., 1992, Improving Higher Education: Total quality care (London, Society for Research in Higher Education/Open University Press).

BARrow, M. \& CURZON-HobSOn, A., 2003, 'From compliance to care: stimulating change in a New Zealand polytechnic', Quality in Higher Education, 9(3), pp. 267-72.

BIGGS, J., 2001, 'The reflective institution: assessing and enhancing the quality of teaching and learning', Higher Education, 41, pp. 221-38. 
BOXER, P., 1985, 'Judging the quality of development', in Boud, D., KEOGH, R. \& WALKER, D. (Eds.) Reflection: Turning experience into learning (London, Kogan Page).

CAfarella, R.S., 2002, Planning Programs for Adult Learners. A practical guide for educators, trainers and staff developers (San Francisco, Jossey-Bass).

CAnnon, R. \& Newble, D., 2002, A Handbook for Teachers in Universities and Colleges: A guide to improving teaching methods (London, Kogan Page).

CARRAD, L., 2002, 'Policy developments in mentoring and volunteering', in MiLler, A. (Ed.) Mentoring,Citizenship and the Community: Report of the third annual conference of the London Mentoring Network (London, Learning and Skills Council).

Chelminsky, E., 1997, 'Thoughts for a new evaluation society', Evaluation, 3(1), pp. 97-118.

Cohen, L., Manion, L. \& Morrison, K., 2000, Research Methods in Education (London, Routledge).

DAVIES, H.T.O., Nutley, S.M. \& SMITH, P.C., 2000, What Works? Evidence-based policy and practice in public services (Bristol, Polity Press).

Foster, D. \& Russell, D. (Eds.), 2002, Writing and learning in Cross-National Perspective. Transitions from secondary to higher education (Urbana, IL, National Council of Teachers of English).

FREEDMAN, M., 1992, The Kindness of Strangers: Reflections on the mentoring movement (Philadelphia, PA, Public/Private Ventures).

Geall, V., Harvey, L. \& MoOn, S., 1997, 'The United Kingdom: institutional selfevaluation and quality', in StrYdom, A.H., LATEGAN, L.O.K. \& Muller, A. (Eds.) Enhancing Institutional Self-Evaluation and Quality in South African Higher Education: National and international perspectives (Bloemfontein, Unit for Research into Higher Education).

Goodlad, S., 1995, Students as Tutors and Mentors (London, Kogan Page).

HaRvey, L. \& GReEn, D., 1993, 'Defining quality', Assessment and Evaluation in Higher Education, 18(1), pp. 9-34.

HARVEY, L. \& NEWTON, J., 2004, 'Transforming quality evaluation', Quality in Higher Education, 10(2), pp. 149-65.

Haworth, J.G. \& CONRAD, C.F., 1997, Emblems of Quality in Higher Education (London, Allyn and Bacon).

LATEGAN, L.O.K., 1997, 'Defining quality for South African universities', in STRYDOM, A.H., LATEGAN, L.O.K. \& Muller, A. (Eds.) Enhancing Institutional Self-Evaluation and Quality in South African Higher Education: National and international perspectives (Bloemfontein, Unit for Research into Higher Education). 
LOMAS, L., 2002, 'Does the development of mass education necessarily mean the end of quality?', Quality in Higher Education, 8(1), pp. 71-9. MedicAl EdUCATION FOR SouTH AFRICAN BlaCKS, 2003, Medical Education for South African Blacks: Mentor programme, available online at: http://www.mesab.org/programmes/mentor.asp (accessed 11 June 2003).

Miller, A., 2002, Mentoring Students and Young People. A handbook for effective practice (London, Kogan Page).

NEwTON, J., 2002, 'Views from below: academic coping with quality', Quality in Higher Education, 8(1), pp. 39-61.

PACE, R., 1984, Measuring the Quality of College Student Experience (Los Angeles, CA, UCLA Center for the Study of Evaluation).

RATCLIFF, J.L., 2003, 'Dynamic and communicative aspects of quality assurance', Quality in Higher Education, 9(2), pp. 117-31.

SCHOn, D.A., 1983, The Reflective Practitioner: How professionals think in action (London, Temple Smith).

STENHOUSE, L., 1987, 'The conduct, analysis and reporting of case study in educational research and evaluation', in MurPheY, R. \& TORRANCE, H. (Eds.) Evaluating Education: Issues and methods (London, Harper and Row).

STEPHENSON, S.L., 2003, 'Saving quality from quality assurance', paper presented at the 15th International Conference: Assessing Quality in Higher Education, Cape Town. TAM, M., 2004, 'Using students' self-reported gains as a measure of value-added', Quality in Higher Education, 10(3), pp. 253-60.

TINTO, V., 1975, 'Dropout from higher education: a theoretical synthesis of recent research', Review of Educational Research, 45, pp. 89-125.

VRoeiJenstiJn, T., 1992, 'External quality assessment, servant of two masters? The Netherlands university perspective', in CRAFT, A. (Ed.) Quality Assurance in Higher Education: Proceedings of an international conference Hong Kong, 1991 (London, Falmer Press).

WATTY, K., 2003, 'When will academics learn about quality?', Quality in Higher Education, 9(3), 213-21. 